\title{
Synthesis, characterization and comparative study the antibacterial activities of some imine-amoxicillin derivatives
}

\author{
Ivan Hameed Rouil Tomi *, Amer Hasan Abdullah, \\ Ali Hussein Raheemah Al-Daraji, and Selma Abdul Rudha Abbass \\ Department of Chemistry, College of Sciences, Al-Mustansiriya University, 10052, Baghdad, Iraq \\ *Corresponding author at: Department of Chemistry, College of Sciences, Al-Mustansiriya University, 10052, Baghdad, Iraq. \\ Tel.: +964.790.1965123; fax: +964.1.4165521. E-mail address: ivanhrtomy@yahoo.com (I.H.R. Tomi).
}

\section{ARTICLE INFORMATION}

Received: 15 February 2013

Received in revised form: 22 March 2013

Accepted: 25 March 2013

Online: 30 June 2013

\section{KEYWORDS}

\begin{tabular}{l} 
Schiff base \\
Amoxicillin \\
Penicillin A \\
Azomethine \\
Imine derivatives \\
Antibacterial activity \\
\hline
\end{tabular}

\section{ABSTRACT}

In this study, we report the synthesis of some new Schiff base compounds (1-5) from the reaction of amoxicillin with some aromatic aldehydes in classical Schiff base method. These derivatives were characterized by melting point, elemental analysis, FT-IR and ${ }^{1} \mathrm{H}$ NMR data. All the synthesized compounds were evaluated in vitro for their antibacterial activities against two Gram positive (Staphylococcus aureus, Streptococcus faecalis) and two Gram negative (Escherichia coli, Pseudomonas aeruginosa) microorganisms in different concentrations $\left(10^{-1}\right.$, $10^{-3}, 10^{-5}$ and $10^{-7} \mathrm{M}$ ) by agar diffusion disk method. The results showed that some of these derivatives have good antibacterial activities compared to biological activity of parent drug.

\section{Introduction}

Amoxicillin (penicillin A), Figure 1, a very popular, safe antibiotic and is usually the drug of choice within the class because it is better absorbed compared to other beta-lactam antibiotics [1]. It is a moderate-spectrum, bacteriolytic, $\beta$ lactam antibiotic used to treat many different types of infections caused by susceptible microorganisms. it is active against a wide range of Gram-positive, and a limited range of Gram-negative organisms [2]. It is also found that amoxicillin and its derivatives are very importance in many research studies, such as pharmaceutical and biological studies [3-6].

Compounds containing an azomethine group (imine) are a class of important compounds in medicinal and pharmaceutical field. The biological applications of these compounds have attracted remarkable attention [7]. Some Schiff-bases were exhibits antibiotic, antiviral and antitumor agents because of their specific structure [8]. The wide use of antibiotics resulted in the serious medical problem of drugs resistance and public health concern. The synthesis of new derivatives of antibiotics has become an important task to cope with drug resistance problems $[9,10]$.

Due to the activities associated with amoxicillin and imines, an attempt was made to generate new derivatives containing imine and amoxicillin in the same molecules (1-5). All the synthesized compounds were further characterized and evaluated for antibacterial activities.

There are many interesting studies on the Schiff bases compounds and their complexes derived from antibiotics. Naz and Iqbal [11] found that the Schiff base complexes derived from amoxicillin having good antibacterial activity in good range when comparison to control (Amoxicillin). Also Joshi et. al. [12] synthesized two ligands derived from amoxicillin and their complexes with many metals that it used in biological activates. He found that the Schiff base ligands were found to be biologically active and their metal complexes display enhanced antimicrobial activity.<smiles>CC1(C)S[C@@H]2[C@H](NC(=O)[C@@H](N)c3ccc(O)cc3)C(=O)N2[C@H]1C(=O)O</smiles>

Figure 1. Amoxicillin structure.

\section{Experimental}

\subsection{Materials and physical measurements}

All reactants and solvents used in this study were reagents grade and they are available from Sigma-Aldrich and Fluka companies. Amoxicillin trihydrate was supplied by Arab Company for Antibiotics Industries (ACAI) in Iraq.

Melting points were determined on Electro-thermal capillary apparatus and are uncorrected. Elemental analysis $(\mathrm{C}$ $\mathrm{H}, \mathrm{N}$ ) were carried out using a Euro-Vector model EA $3000 \mathrm{~A}$ instrument. The FT-IR spectra were obtained using SHIMADZU model FT-IR-8400S. ${ }^{1} \mathrm{H}$ NMR spectra were obtained on BRUKER model Ultra shield $300 \mathrm{MHz}$ spectrophotometer in DMSO-d6 solution with the TMS as internal standard. 
Table 1. Physical properties, elemental analysis and FT-IR data of compounds (1-5).

\begin{tabular}{|c|c|c|c|c|c|c|}
\hline \multirow[t]{2}{*}{ Compound } & \multirow[t]{2}{*}{ M.p., ${ }^{\circ} \mathrm{C}$} & \multirow[t]{2}{*}{ Yield, \% } & \multirow{2}{*}{$\begin{array}{l}\text { FT-IR, } \text { cm}^{-1} \\
\text { CH=N }\end{array}$} & \multicolumn{3}{|c|}{ Elemental analysis, calculated (found), $\%$} \\
\hline & & & & $\mathbf{C}$ & H & $\mathbf{N}$ \\
\hline$\overline{1}$ & $179-182$ & 77 & 1664 & $55.41(55.23)$ & $4.45(4.21)$ & $11.24(11.16)$ \\
\hline 2 & 209-211 (Dec.) & 62 & 1662 & $61.65(61.70)$ & $5.39(5.51)$ & $8.99(9.04)$ \\
\hline 3 & $218-220$ & 67 & 1664 & $59.61(59.66)$ & $5.21(5.12)$ & $8.69(8.61)$ \\
\hline 4 & $215-216$ & 71 & 1663 & $56.61(56.50)$ & $4.54(4.60)$ & $8.61(8.55)$ \\
\hline 5 & $188-190$ & 83 & 1666 & $51.89(52.02)$ & $4.16(4.27)$ & $7.89(7.95)$ \\
\hline
\end{tabular}

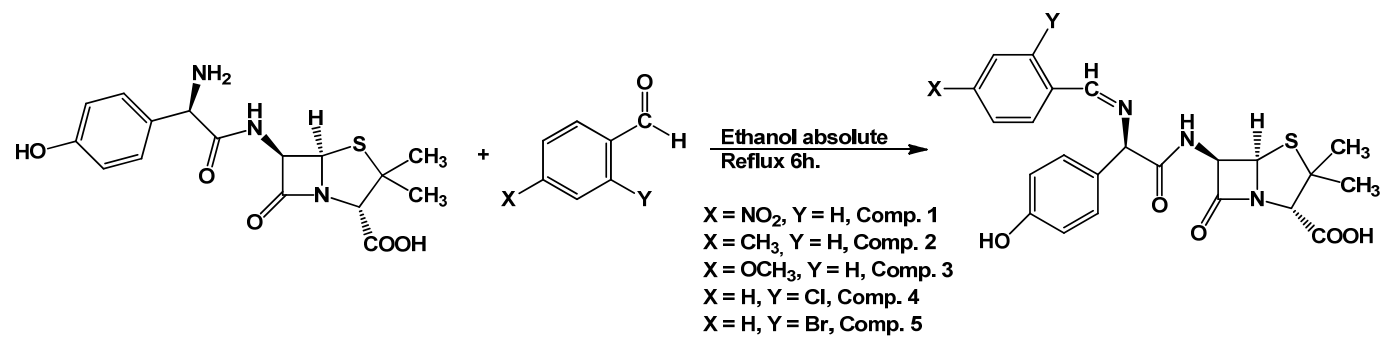

Scheme 1

2.1.1. General method for the preparation of $(5 R, 6 R)-6-\{[(E)-$ substitutedbenzilidene]amino\}-2-(4-hydroxyphenyl) acetyl] amino\}-3,3-dimethyl-7-oxo-4-thia-1-azabicyclo[3.2.0] heptane-2-carboxylic acid (1-5)

The Schiff bases derived from substituted benzaldehydes and amoxicillin trihydrate were prepared using a modified method similar to one given by Joshi et al. and Al-Garawi et al. $[12,13]$. A solution of substituted benzaldehydes $(1.1 \mathrm{mmol})$ in ethanol $(10 \mathrm{~mL})$ and amoxicillin trihydrate $(0.419 \mathrm{~g}, 1.0 \mathrm{mmol})$ were mixed. The obtained solution was then magnetically stirred and refluxed for $6 \mathrm{~h}$ at boiling temperature. The obtained brownish red solution was poured in cold water $(100$ $\mathrm{mL}$ ). The solid was filtered and washed several times with water then dried in air for $2 \mathrm{~h}$.

\subsubsection{General method for determination the antibacterial activity of Schiff base compounds (1-5)}

The prepared compounds (1-5) were screened for antibacterial activities using cup-plate agar diffusion method by measuring the inhibition zone in $\mathrm{mm}[14,15]$. Amoxicillin in different concentrations $\left(10^{-1}, 10^{-3}, 10^{-5}\right.$ and $\left.10^{-7} \mathrm{M}\right)$ was used as a standard drug for comparative antibacterial activity of the prepared compounds. The compounds were screened for antibacterial activity against two Gram positive (Staphylococcus aureus, Streptococcus faecalis) and two Gram negative (Escherichia coli, Pseudomonas aeruginosa) microorganisms that have been isolated from infected wounds, nose swab, urinary tract infection, surgical theaters, respectively, in Muller Hinton agar. These sterilized agar media were poured into Petri-dishes and allowed to solidify. On the surface of the media microbial suspensions were spread with the help of sterilized triangular loop. A stainless steel cylinder of $12 \mathrm{~mm}$ diameter (pre-sterilized) was used to bore cavities. All the synthesized compounds in different concentrations $\left(10^{-1}, 10^{-3}, 10^{-5}\right.$ and $10^{-7}$ M) were placed serially in cavities with the help of micropipette and allowed to diffuse for one hr. DMSO was used as a solvent for all compounds and sterile distilled water was used as a solvent for pure amoxicillin. These plates were incubated at 37 ${ }^{\circ} \mathrm{C}$ for $48 \mathrm{hr}$. The zone of inhibition observed around the cups after respective incubation was measured in $\mathrm{mm}$.

\section{Results and discussions}

\subsection{Synthesis}

Scheme 1 outline the synthetic sequences employed in our laboratories for preparation of Schiff base compounds (1-5).
The Schiff base derivatives of amoxicillin were prepared in good yield by the reaction of the corresponding benzaldehydes with amoxicillin trihydrate in absolute ethanol as a solvent. The structural assignment of amoxicillin trihydrate was based on melting point (182-184 ${ }^{\circ} \mathrm{C}$ decomposed) and their spectral FTIR spectroscopy. The FT-IR spectrum of this antibiotic exhibited significant two bands at 3332 and $3163 \mathrm{~cm}^{-1}$ which could be attributed to asymmetric and symmetric stretching vibrations of $\mathrm{NH}_{2}$ group. Besides this, bands about 1776 and $1687 \mathrm{~cm}^{-1}$ are due to $\mathrm{C}=0$ stretching for lactam and carboxyl groups respectively. It also showed a broad band between 3041-2621 $\mathrm{cm}^{-1}$ due to stretching $0-\mathrm{H}$ of carboxyl group (v $\mathrm{COOH}$ ). The bands that appeared at 3527 and $3462 \mathrm{~cm}^{-1}$ were assigned to the amide $(\mathrm{N}-\mathrm{H})$ and hydroxyl group $(\mathrm{O}-\mathrm{H})$ respectively.

The FT-IR spectra of compounds (1-5) indicated the presence of $\mathrm{CH}=\mathrm{N}$ function $\left(1662-1666 \mathrm{~cm}^{-1}\right)$ and disappearances two bands at $\left(3332 \mathrm{~cm}^{-1}\right)$ and $\left(3163 \mathrm{~cm}^{-1}\right)$ which could be attributed to asymmetric and symmetric stretching vibration of $\mathrm{NH}_{2}$ group of amoxicillin. Reviews on ${ }^{1} \mathrm{H}$ NMR of Amoxicillin. $3 \mathrm{H}_{2} \mathrm{O}$ in DMSO- $d_{6}$ solvent is available in references $[16,17]$. The amine and carboxyl protons did not observed in the spectrum because the extent of intermolecular interactions with DMSO $-d_{6}[18,19]$. The ${ }^{1} \mathrm{H}$ NMR spectra of these compounds 1-5 showed a singlet at $\delta 10.03,9.98,9.93,9.87$ and $10.29 \mathrm{ppm}$ due to the imines protons, respectively. The physical properties and FT-IR data for Schiff bases derivatives are listed in Table 1 and the ${ }^{1} \mathrm{H}$ NMR data are listed in Table 2.

\subsection{Antibacterial studies}

All the synthesized compounds (1-5) with parent drug (Amoxicillin tri hydrate) have been screened in vitro for antibacterial activities.

When we examine the data of (inhibition zone) of all compounds (1-5) against Staphylococcus aureus in Figure 2, we observe some important results: that the compounds 3,4 and 5 showed biological activities more than the parent drug and that these activities increases with increasing the concentration of these compounds while compounds $\mathbf{1}$ and $\mathbf{2}$ showed the opposite. Also, the compound $\mathbf{3}$ has a biological activity higher than the compounds $\mathbf{4}$ and $\mathbf{5}$.

We note from Figure 3, the activity against Streptococcus faecalis, that all the prepared compounds, except compound $\mathbf{1}$, have higher biological activities than the pure amoxicillin and this efficiency increases with increasing the concentration of compounds, also the compound $\mathbf{5}$ has the highest activity against this type of bacteria compared to others. 


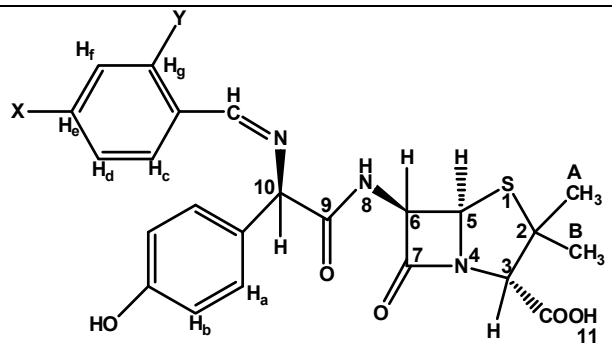

\begin{tabular}{|c|c|c|c|c|c|c|}
\hline Assignment & Amoxicillin. $3 \mathrm{H}_{2} \mathrm{O}^{\mathrm{b}}$ & Compound 1 & Compound 2 & Compound 3 & Compound 4 & Compound 5 \\
\hline $\mathrm{A}-\mathrm{CH}_{3}$ & $1.38(\mathrm{~s})$ & $1.31(\mathrm{~s})$ & $1.21(\mathrm{~s})$ & $1.32(\mathrm{~s})$ & $1.34(\mathrm{~s})$ & $1.39(\mathrm{~s})$ \\
\hline $\mathrm{B}-\mathrm{CH}_{3}$ & $1.49(\mathrm{~s})$ & $1.56(\mathrm{~s})$ & $1.48(\mathrm{~s})$ & $1.50(\mathrm{~s})$ & $1.48(\mathrm{~s})$ & $1.54(\mathrm{~s})$ \\
\hline $\mathrm{H}-3$ & $3.98(\mathrm{~s})$ & $3.99(\mathrm{~s})$ & $4.39(\mathrm{~s})$ & $3.86(\mathrm{~s})$ & $3.97(\mathrm{~s})$ & $3.99(\mathrm{~s})$ \\
\hline $\mathrm{H}-10$ & $4.87(\mathrm{~s})$ & $4.76(\mathrm{~s})$ & $4.82(\mathrm{~s})$ & $4.79(\mathrm{~s})$ & $4.81(\mathrm{~s})$ & $4.83(\mathrm{~s})$ \\
\hline $\mathrm{H}-5$ & $5.32(d)$ & 5.29 (d) & 5.39 (d) & 5.44 (d) & $5.33(\mathrm{~s})$ & $5.37(\mathrm{~s})$ \\
\hline H-6 & $5.50(\mathrm{~s}, \mathrm{bd})$ & $5.68(\mathrm{~s}, \mathrm{bd})$ & $5.51(\mathrm{~s}, \mathrm{bd})$ & $5.66(\mathrm{~s}, \mathrm{bd})$ & $5.69(\mathrm{~s}, \mathrm{bd})$ & $5.61(\mathrm{~s}, \mathrm{bd})$ \\
\hline $\mathrm{H}_{\mathrm{a}}$ & $6.77(d)$ & $6.74(d)$ & $6.69(d)$ & $6.67(d)$ & $6.68(d)$ & $6.70(d)$ \\
\hline $\mathrm{H}_{\mathrm{b}}$ & 7.30 (d) & 7.33 (d) & 7.21 (d) & 7.25 (d) & $7.23(d)$ & 7.20 (d) \\
\hline $\mathrm{NH}$ & $8.68(d)$ & $8.61(d)$ & 8.59 (d) & $8.56(d)$ & $8.63(d)$ & $8.61(d)$ \\
\hline $\mathrm{OH}$ & $9.05(d)$ & $9.16(d)$ & 9.11 (d) & 9.14 (d) & 9.09 (d) & 9.12 (d) \\
\hline $\mathrm{NH}_{2}$ & Not observed & - & - & - & - & - \\
\hline $\mathrm{CH}=\mathrm{N}$ & - & $10.03(\mathrm{~s})$ & $10.01(\mathrm{~s})$ & $9.98(\mathrm{~s})$ & $10.02(\mathrm{~s})$ & $10.12(\mathrm{~s})$ \\
\hline $\mathrm{COOH}$ & Not observed & $11.07(\mathrm{~s})$ & $11.09(\mathrm{~s})$ & $11.10(\mathrm{~s})$ & $11.02(\mathrm{~s})$ & $11.04(\mathrm{~s})$ \\
\hline $\mathrm{H}_{\mathrm{c}}$ & - & 7.81 (d) & 7.79 (d) & $7.86(\mathrm{~s})$ & 7.61 (d) & $7.66(d)$ \\
\hline $\mathrm{H}_{\mathrm{d}}$ & - & 8.32 (d) & 8.37 (d) & 8.40 (d) & $8.18(t)$ & $8.16(t)$ \\
\hline $\mathrm{H}_{\mathrm{e}}$ & - & - & - & - & $8.27(\mathrm{t})$ & $8.22(\mathrm{t})$ \\
\hline $\mathrm{H}_{\mathrm{f}}$ & - & $8.32(d)$ & $8.37(d)$ & $8.40(d)$ & $8.36(d)$ & $8.41(d)$ \\
\hline $\mathrm{H}_{\mathrm{g}}$ & - & 7.81 (d) & 7.79 (d) & $7.86(d)$ & - & - \\
\hline$x^{b}$ & - & - & $2.26(\mathrm{~s})$ & $4.04(\mathrm{~s})$ & - & - \\
\hline Y & - & - & - & - & - & - \\
\hline
\end{tabular}

Abbreviations: $\mathrm{s}=$ singlet; $\mathrm{d}=$ doublet; $\mathrm{t}=$ triplet; $\mathrm{bd}=$ broad

b The data was taken from the references $[16,17]$.

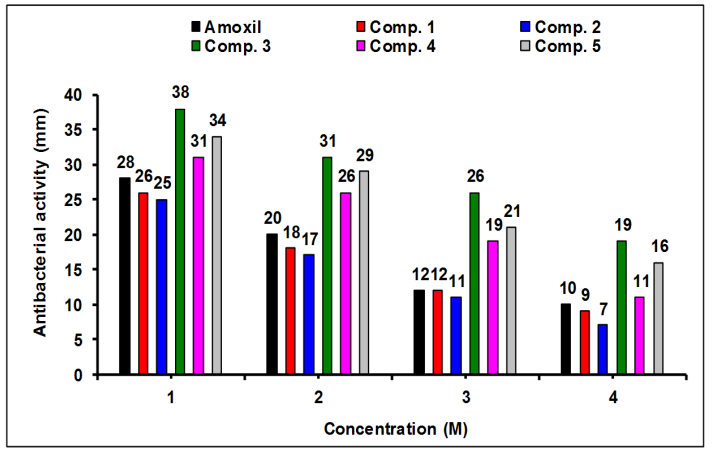

Figure 2. The activity of compounds (1-5) against Staphylococcus aureus in different concentrations $\left(1=10^{-1}, 2=10^{-3}, 3=10^{-5}\right.$, and $\left.4=10^{-7} \mathrm{M}\right)$.

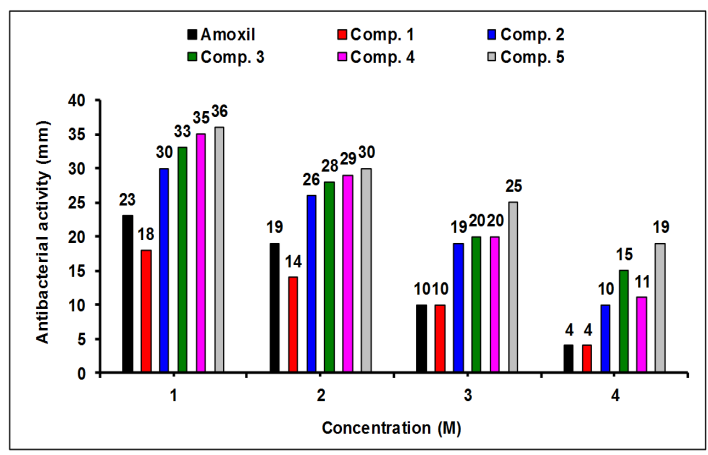

Figure 3. The activity of compounds (1-5) against Enterococcus faecalis in different concentrations $\left(1=10^{-1}, 2=10^{-3}, 3=10^{-5}\right.$, and $\left.4=10^{-7} \mathrm{M}\right)$.
When comparing the biological activities of two types of Gram possitive (Staphylococcus aureus and Streptococcus faecalis) for all compounds we find that compound $\mathbf{3}$ retains its high effectiveness among all the derivatives and show potent activity against Staphylococcus aureus.

On the other hand, when we show the results of activity against Escherichia coli, Figure 4, we observed some important notes: the first that all compounds (1-5) in all concentrations have good activity against this bacteria and this inhibition increases with increasing the concentration of compounds. The second is the compound $\mathbf{5}$ has good activity compared to others.

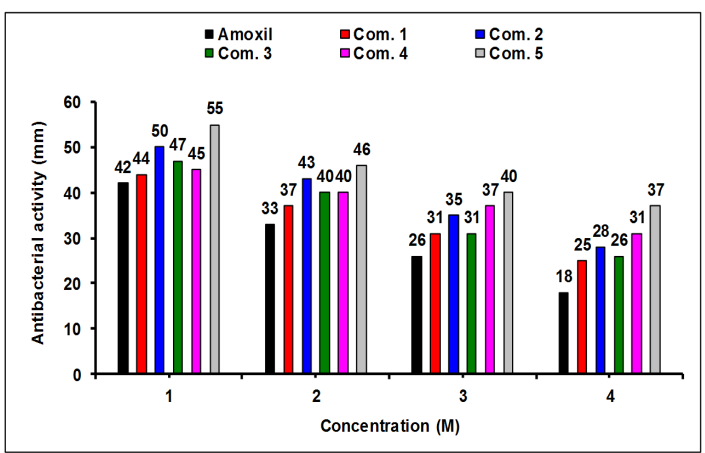

Figure 4. The activity of compounds (1-5) against Escherichia coli in different concentrations $\left(1=10^{-1}, 2=10^{-3}, 3=10^{-5}\right.$ and $\left.4=10^{-7} \mathrm{M}\right)$.

When we assess the results of the biological activity of the compounds (1-5) against Pseudomonas aeruginosa, Figure 5, we find that only two compounds ( 2 and 3 ) have shown the activity higher than amoxicillin, while compounds $\mathbf{4}$ and $\mathbf{5}$ showed less activity than pure amoxicillin note that with the 
activity of compound $\mathbf{1}$ towards these bacteria almost similar to the activity of parent drug.

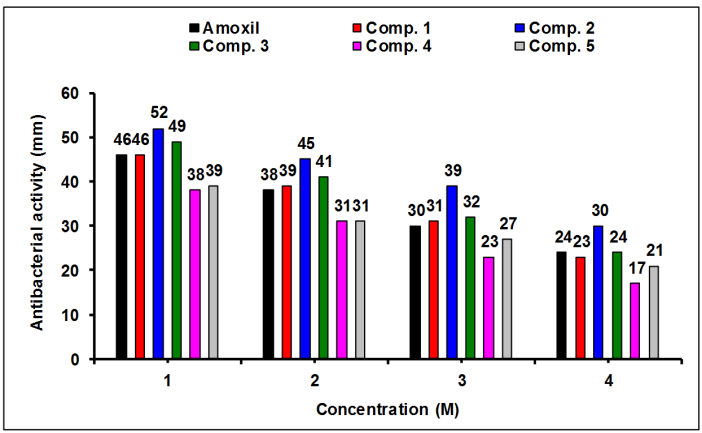

Figure 5. The activity of compounds (1-5) against Pseudomonas aeruginosa in different concentrations $\left(1=10^{-1}, 2=10^{-3}, 3=10^{-5}\right.$, and $\left.4=10^{-7} \mathrm{M}\right)$.

\section{Conclusions}

Schiff base compounds derived from amoxicillin trihydrate were prepared and structurally characterized using spectroscopic techniques. The synthetic route started from reaction between amoxicyllin and appropriate substituted benzaldehydes (4-nitro benzaldehyde, 4-methyl benzaldehyde, 4-methoxy benzaldehyde, 2-chloro benzaldehyde and 2-bromo benzaldehyde) in ethanol. The Schiff base compounds containing amoxicillin moiety have been evaluated in vitro for their antimicrobial activities against two types of bacteria: Gram positive (Staphylococcus aureus, Streptococcus faecalis) and Gram negative (Escherichia coli, Pseudomonas aeruginosa) microorganisms in different concentrations $\left(10^{-1}, 10^{-3}, 10^{-5}\right.$ and $10^{-7} \mathrm{M}$ ). The results showed that some of these derivatives have good antibacterial activity compared to the parent drug.

\section{Acknowledgments}

We thank Mr. Mohanad Husein Mohamad Masad (Al AlBayt University, Jordan) for helpful about doing the ${ }^{1} \mathrm{H}$ NMR spectra and elemental analysis for all prepared compounds, and Mrs. Zainab Kadim Mohammed Jawad (Al-Mustansiriya University, Chem. Dept., Iraq) about doing the FT-IR spectra. Also we would like to express our sincere gratitude to ACAI company in Iraq for supplying the parent drug (Amoxicillin trihydrate).

\section{References}

[1]. Unal, A.; Palabiyik, L.; Karacan, E.; Onur, F. Turk. Pharm. Sci. 2008, 5, 1-16.

[2]. Bisson-Boutelliez, C.; Fontanay, S.; Finance, C., Kedzierewicz, F. AAPS Pharm. Sci. Tech. 2010, 11, 574-581.

[3]. Jodeh, S.; Stati, H.; Haddad, M.; Renno, T.; Zaid, A.; Jaradat, N.; Kharoaf, M. Eur. J. Chem. 2012, 3(4), 480-484.

[4]. Jodeh, S. Eur. J. Chem. 2012, 3(4), 468-474.

[5]. Sivakumar, R.; Pradeepchandran, R. V.; Jayaveera, K. N. Eur. J. Chem. 2011, 2(4), 558-560

[6]. El-Sawi, E. A.; Mostafa, T. B.; Radwan, H. A. Eur. J. Chem. 2011, 2(4), 539-543.

[7]. Imran, M.; Iqbal, J.; Iqbal, S.; Ijaz, N. Turk. J. Biol. 2007, 31, 67-72.

[8]. Parekh, H. M.; Patel, M. N. Russian J. Coord. Chem. 2006, 32, 431-436.

[9]. Singh, K.; Barwa, M. S.; Tyagi, P. Eur. J. Med. Chem. 2007, 42, 394-402.

[10]. Bagihalli, G. B.; Avaji, P. G.; Patil, S. A.; Badami, P. S. Eur. J. Med. Chem. 2008, $43,2639-2649$.

[11]. Naz, N.; Iqbal, M. Z. J. Chem. Soc. Pak. 2009, 31, 440-446.

[12]. Joshi, S.; Pawar, V.; Uma, V. Int. J. Pharm. Bio Sci. 2011, 2, 240-250.

[13]. Al-Garawi, Z. S. M.; Tomi, I. H. R.; Al-Daraji, A. H. R. E-Journal Chem. 2012, 9(2), 962-969.

[14]. Tomi, I. H. R.; Al-Daraji, A. H. R.; Al-Qaysi, R. R. T.; Hasson, M. M.; AlDulaimy, K. H. Arabian J. Chem. 2011 http://dx.doi.org/10.1016/ i.arabic.2010.12.003

[15]. Panda, S. S.; Chowdary. P.; Jayashree, B. S. Indian J. Pharm. Sci. 2009, 71(6), 684-687.
[16]. Branch, S. K.; Casy, A. F.; Lipczynsky, A.; Ominde, E. M. A. Magn. Reson Chem. 1986, 24, 465-479.

[17]. Branch, S. K.; Casy, A. F.; Ominde, E. M. A. J. Pharm. Biomed. Anal. 1987, 5, 73-103.

[18]. Kupka, T.; Dziegielewski, J. O.; Pasterna, G. J. Pharm. Biomed. Anal. 1993, 11, 103-116.

[19]. Stefano, R. D.; Scopelliti, M.; Pellerito, C.; Fiore, T.; Vitturi, R.; Colomba M. S.; Gianguzza, P.; Stocco, G. C.; Consiglio, M.; Pellerito, L. J. Inorg Biochem. 2002, 89, 279-292. 